\title{
Variations in physiotherapy practices across reablement settings
}

\section{$\underline{\text { ABSTRACT }}$}

\section{Background}

Reablement aims to improve the self-dependence of people with or at risk of functional decline.

Physiotherapists (PTs) are responsible for assessments, developing interventions and supervising home trainers (HTs), who mostly conduct the reablement training. The content of reablement practice is not clearly described. This study explores how physiotherapy practice is performed in reablement settings and the content of the service provided to reablement users.

\section{$\underline{\text { Methods }}$}

Fieldwork was performed in seven Norwegian reablement teams. We conducted observations of seven triads, including PTs, HTs, and reablement users, followed by interviews with the PTs and HTs. We then conducted a systematic content analysis.

\section{$\underline{\text { Results }}$}

Three themes emerged from the analysis: 1) division of labor, 2) assessment, and 3) intervention.

Different practices within these three characteristics of practice revealed two typologies of reablement teams. Teams with a fixed division of labor provided limited assessments and a non-specific approach. Teams with a flexible division of labor were characterized by interdisciplinary collaboration, thorough assessments and user-tailored interventions.

\section{$\underline{\text { Discussion }}$}

Values emphasizing responsivity enable a flexible and individually tailored reablement approach, in contrast to values emphasizing efficiency, which facilitate a non-specific approach.

\section{Keywords}

Division of labor, home-based rehabilitation, interprofessional, multi-professional, cooperation 


\section{$\underline{\text { INTRODUCTION }}$}

Reablement is an intensive, time-limited, person-centered, goal-oriented intervention for people with or at risk of functional decline (Aspinal, et al., 2016; Tessier, Beaulieu, Mcginn, and Latulippe, 2016). An interdisciplinary team conducts the approach in the users' home environment, aiming to encourage them to live independent lives (Cochrane, et al., 2016). Internationally, various terms for reablement have been used, including restorative home care (Australia and US) (Ryburn, Wells, and Foreman, 2009; Tinetti, et al., 2002), re-ablement (UK) (Rabiee and Glendinning, 2011) and everyday rehabilitation (Scandinavia) (Moe and Brataas, 2016). The terms appear to be inconsistent. Furthermore, the lack of agreed specified set of clinical and demographic characteristics makes the target population highly heterogenous and difficult to define (Legg, Gladman, Drummond, and Davidson, 2016). Scholars have even merged different terms and developed the concept ' $4 \mathrm{R}$ ' to over define health care services for people who need support to live at home (Sims-Gould, Tong, Wallis-Mayer, and Ashe, 2017). Systematic reviews have concluded that there is neither established solid evidence of an effect regarding health benefits and governmental cost efficiency (Cochrane, et al., 2016; Legg, Gladman, Drummond, and Davidson, 2016) nor a clear description of a conceptual or theoretical framework to define the content of the service (Legg, Gladman, Drummond, and Davidson, 2016). More high quality research is required to determine the concept of and effect of reablement (Cochrane, et al., 2016; Legg, Gladman, Drummond, and Davidson, 2016; Pettersson and Iwarsson, 2017).

Norwegian health and social care services are publicly funded and should be offered to all citizens regardless of their financial situation, social status, gender or age. An increasing number of older adults and a growing demand for complex services have placed pressure on local governments to offer proactive interventions to strengthen citizens' ability to remain independent in their home environment. The goal is to delay and reduce demands for long-term support from health care services (Norwegian Ministry of Health and Care Services, 2015). The Norwegian government has suggested reablement as an approach for people with or at risk of functional decline. Allthough reablement shares features with other rehabilitation services, Norwegian authorities emphasize that reablement should be provided to a large extent by home care workers, in contrast to traditional rehabilitation 
services, which are provided by health professionals (Norwegian Ministry of Health and Care Services, 2015).This solution aims to meet the challenges in Norwegian health care services.

Despite the lack of evidence of effect, the Norwegian government allocated 63.4 million NOK (8.4 million US dollars) in the period from 2013 to 2015 to implement reablement services within 47 Norwegian municipalities (Langeland, et al., 2016).

To improve the knowledge base for reablement in Norway, the Norwegian Association of Local and Regional Authorities initiated a report on reablement practices in Norwegian municipalities (Fürst \& Høverstad ANS, 2014). Two main models were described in the Norwegian context: 1) a specialist model and 2) an integrated model. The first model consisted of multidisciplinary teams including physiotherapists (PTs), occupational therapists (OTs), nurses and home trainers (HTs). These teams were organized independent of the traditional home care services and were working exclusively with reablement users. .The second model was incorporated into the traditional home care service. Personnel from the home care service were supposed to conduct the reablement training initiatives under supervision by the therapists but were still expected to fulfill their regular home care services (Fürst \& Høverstad ANS, 2014). A Norwegian study aimed to investigate the efficiency of different models of reablement. Based on a multi-level analysis of 36 reablement teams in 33 Norwegian municipalities, the study concluded that the choice of model did not have any significant effect on user performance and user satisfaction with performance in daily activities (Langeland, et al., 2016). However, the study had weaknesses regarding sample size and a lack of description of content of practice, while classification of the models was limited to involving administrative organization.

The Norwegian Association of Local and Regional Authorities' report identified some common assessment tools; The Canadian Occupational Performance Measure (COPM) and the Short Physical Performance Battery (SPPB) have frequently been used in reablement (Fürst \& Høverstad ANS, 2014; Tuntland, et al., 2016). The use of these tests was mandatory for the reablement teams in the aforementioned 47 municipalities (Langeland, et al., 2016), and they have also been widely suggested as assessment tools for other reablement teams (Førland and Skumsnes, 2016; Fürst \& Høverstad ANS, 2014; Ness, et al., 2012). The COPM was designed to identify, prioritize and evaluate performance and satisfaction with the performance of activities self-identified as important to users' 
lives (Carswell, et al., 2004). The SPPB is a screening test that identifies risk of functional decline (Gomez, et al., 2013).

Reablement intervention is described as involving both physical exercises and guidance in everyday activities (Hjelle, Tuntland, Forland, and Alvsvag, 2017; Langeland, et al., 2016). Beyond this, we found no descriptions that could provide insight into the actual events and interactions in practical interventions; thus, we gained little specific knowledge about the service offered to reablement users.

The lack of description of content of reablement may give rise to a varied practice with varying quality. The Norwegian Association of Local and Regional Authorities (Fürst \& Høverstad ANS, 2014) states that reablement is an appealing solution to ensure quality in health and care services in an efficient manner and that quality and efficiency should be emphasized as equally important. Studies of practice may reveal how these potentially conflicting values (cf. Hood, 1991) are played out in reablement service.

In Norway, PTs play a core role in reablement by contributing to assessments and guiding HTs regarding exercises tailored to the user's individual function (Ness, et al., 2012). Basic to physiotherapy practice is the use of specific knowledge and skills to identify potential for movement and to maximize quality of life (World Confederation for Physical Therapy, 2016). Individual examinations and clinical reasoning are fundamental to tailored and individualized interventions and treatment (Johnson and Thompson, 1996).

We wanted to investigate how physiotherapy was integrated into clinical interventions in reablement, including the clinical reasoning and rationales that the intervention was based on. The extended use of care workers, without training or education in essential skills and knowledge, to perform home training may be a barrier to optimal and well-tailored interventions. Therefore, we also wanted to explore the service provided to users by HTs. This study targeted reablement practice in both specialist teams and integrated teams.

The aim of this study was to explore how physiotherapy practice is performed in reablement settings and the content of the service provided to reablement users. 


\section{$\underline{\text { METHODS }}$}

In this exploratory study, we used qualitative methods. Our interpretation is that people within a social world both construct and perceive the meaning of the world and thereby create a taken-forgranted reality that forms their practices (Andrews, 2012). Aiming to explore the content of interactions in practice, the results were generated in a social constructionist perspective. We collected data by observing PTs and HTs in their work environment and observing reablement sessions with users. Based on these observations, we conducted interviews with both PTs and HTs after the sessions.

\section{Study setting}

This study was conducted in seven reablement teams within seven different Norwegian municipalities. The municipalities were strategically chosen to obtain a varied population size. The observations of practice in the work environment were conducted at the participants' workplace, which entailed open landscape offices and meeting rooms. The observations of reablement interventions occurred in the users' homes. We conducted all the interviews immediately after the observations in meeting rooms at the PTs' and HTs' work place.

\section{Participants and recruitment}

A triad from each team (seven triads in total) containing one PT, one HT and one user was included. The inclusion criterion for the PTs and HTs was at least 6 months of experience with reablement. The inclusion criterion for the users was that they were about to begin or were in the first week of reablement. All users had to be able to consent to participate; those with cognitive impairment were therefore excluded. Except for being offered reablement service, we had no inclusion criterion for the users regarding age, gender or diagnosis.

General managers of the teams were contacted and informed about the study. After agreeing to participate in the study, the managers distributed information about the study to PTs and HTs. The PTs then recruited users who were about to receive reablement. Written information was distributed, and when a user agreed to participate in the study, the PT contacted the first author (ME) to arrange data 
collection. Co-workers of the included PTs and HTs were also treated as participants, as they were subject to observations in the work environment. Table 1 provides further information about the PTs, HTs and users.

\section{Data collection}

The first author (ME), who is a researcher and a PT, collected data from January to June 2016. To ensure that we captured the practice of physiotherapy assessment, the reasoning that is the foundation of therapeutic plans, and the service provided to the users by HTs, we visited the triad twice. The first visit was conducted during the user's first week of reablement, followed by a second visit two to three weeks later. The key points of the observation guide were 1) treatment setting, 2) content of actions regarding assessments or training, 3) instructions, 4) verbal- and non-verbal communication, and 5) changes in the user's function or movement. The intervention was videorecorded to ensure that the situated and interactional accomplishments of practical action were captured (cf. Heath, Hindmarsh, and Luff, 2011). It was essential for the aim of this study to analyze the fine details of how both the PTs and the HTs interacted with each other and the users. In a clinical setting, multiple components of interactions and bodily movements occur simultaneously. Video use is recommended as a tool to grapple with the complex character of practice and to capture the small details that are inextricably embedded within interactions but are barely conscious to the participants (Heath, Luff, and Svensson, 2007).

The researcher (ME) used a discreet, handheld camera and primarily remained in the background to avoid disturbing the interactions of the participants. A wide video angle was used to capture all three participants, although when it was found essential, she discreetly moved closer or zoomed in through the camera to obtain a closer observation of the users' smaller movements.

During the first visit, the researcher observed the user interventions when both the PT and the HT were present with the user. Immediately after the first observation, the researcher conducted an interview with the PT. The previously observed user intervention was the main topic for the interviews, and clinical reasoning was discussed. 
At the second visit, video-recorded observation of the interactions between the HT and the user was conducted, followed by an interview with the HT that reflected on the preceding observation. Interviews with both the PTs and HTs were semi-structured, with open-ended questions and relevant follow-up questions (Appendix). The interviewees were encouraged to speak freely about their experiences and clinical reasoning. All the interviews were audio-recorded.

In addition to the observations and interviews, field observations of the reablement team's work environment were conducted to examine the context that serves as a framework for the practice. The researcher (ME) followed the PTs and the HTs from six of the triads at their work place (one team was excluded from the observations in their office due to disapproval of co-workers). Two days of observations of both formal meetings and informal meetings were conducted. The current appearance of the work environment, internal communication within the teams regarding professional discussions, exchanges of clinical knowledge, and instructions and guidance were noted.

The combination of observations and interviews provided us with the following complementary information approximately: 1) the interaction in its original context;2) the organizational structure of the interaction; and 3) the clinical reasoning and reflections, which are essential for how the practice is performed. These data gave us rich and detailed material.

Data analysis

We conducted a four-step systematic content analysis inspired by Malterud (2012). We considered this approach appropriate for analyzing data from both interviews and observations, which enabled us to merge the data. ME had the primary responsibility for transcribing, coding and the initial sorting of the data. Further, NH and SM (a sociologist and a PT, both experienced researchers) contributed to the analysis through discussions in regular collaborative meetings.

During the first step, ME developed a summary text after all the research interventions, where overall impressions were noted. Further, all raw material was transformed into text material. The interviews were transcribed verbatim, while the video observations were transcribed and described in a scheme in which six aspects of interactions were categorized: 1) what was done, 2) how it was done, 3) explanation or reasoning, 4) instructions provided, 5) guidance provided, and 6) communication. These categories were predetermined based on the key point in the observation guide and included 
both verbal and bodily interactions. This way of cataloguing video-recorded data was inspired by Heath, Luff, and Svensson (2007) to capture the multiple aspects of interactions in video observations. At first, the basic aspects of the activities and events were written down. Transcriptions of conversation were not rigidly verbatim, although the essence of meaning of conversation was incorporated with the actions described in the different categories in the scheme. Throughout the analysis, descriptions were made more detailed. During several substantial views of the videos, some fragments appeared as especially essential for the aim of the paper. These fragments were further described in even more detail. In this way, the scheme was continuously elaborated regarding the visible and verbal content throughout the process (Heath, Luff, and Svensson, 2007).

During the second step, we identified and coded meaningful units in all text material from all data sources, which were further linked together, supplementing each other. The observation material provided a third-person perspective on the actions and interactions that occurred in the practical setting where it was provided. The interviews elaborated this through insights into the rationales and reasoning that the practice was based on. Initially, 16 codes were identified and sorted through an iterative process.. Searching for correspondence and deviations, we found considerable variations within the three themes, and two typologies of working methods evolved. We refer to these typologies as fixed reablement teams and flexible reablement teams in the remainder of this paper. This clear distinction of structural frames in reablement settings caught our interest and contributed to further structuring of the data material.

During the third step, we developed a summary text for each subgroup based on central quotes. The fragmented observations were summarized in a text that provides examples of actions essential for the aim of this paper.

During the fourth step, we re-conceptualized the subgroups by developing an analytical text based on the most salient content of the data, thorough deliberations of the initial text material and preliminary topics. The final texts are presented in the results section. Central quotes from the interviews are presented in the text and summarizing extracts of the observations are provided in figures and outline the essence of the practice. The analysis was supported by the use of QSR NVivo 11 (QSR International) qualitative data analysis software. 
Table 2 presents the analysis process in a schematic way. Although the process may seem linear and rigorous, following predetermined steps, this was not the case. The analyses were performed as an iterative process, continuously moving between interpretations, relevant theory and the data material (the video material was watched several times). Discussions occurred in regular meetings with all three authors. Theoretical interpretation (Malterud, 2016) contributed to develop and validate the findings. Triangulation of multiple data sources was achieved by linking the data through common code groups. Congruent data from all three methods supported and validated each other, while discrepancies were further analyzed to achieve an understanding of the inconsistency. This iterative process contributed to the validation of our findings.

$\underline{\text { Ethics }}$

This study was approved by the Norwegian Centre for Research Data (Norwegian Centre for Research Data 2017) (Ref number 44747) and was conducted according to the Helsinki Declaration (World Medical Association 2017). All participants received written information about the study and provided written consent before the data were collected. Data were managed confidentially and with respect.

\section{RESULTS}

In total, the data included 14 interviews approximately 45-90 minutes in length and 14 observations of user sessions lasting from 20 to 90 minutes (12 of them were videotaped, and two were audiotaped due to the user's request). Through the analysis of video observations, interviews and field notes, three themes representing three features of practice in reablement emerged: 1) division of labor, 2) assessment and 3) intervention. Based on variations in the data regarding these themes, two typologies of reablement teams were established: fixed structured and flexibly structured teams (Table 3). Characteristics of the respective typologies are presented in all three themes. Important quotations from the interviews are presented in italics, while illustrative excerpts from the observations are presented in figures. 


\section{$\underline{\text { Division of labor }}$}

Field observations, elaborated with the participants' reflections from the interviews, highlighted some feature characteristics of roles and interactions, which influenced the division of labor in the teams. There was a clear difference between the two typologies of reablement teams.

One characteristic of the fixed structured teams was that the PTs and the HTs played different roles. PTs, in addition to the OTs and nurses, were designated "catalysts" of the teams who performed assessments and created reablement plans. In contrast, the HTs appeared as assistants who followed instructions from the "catalysts". The reablement process was scheduled with certain fixed meeting points for the "catalysts" to visit the users: during the implementation, halfway through rehabilitation and at the end of the rehabilitation process. These meetings included informational sessions, baseline assessments, implementation of exercises, and retesting at the end of treatment.

Field observations revealed that in a typical team meeting, the "catalysts" led the discussions, while the HTs largely remained silent. Primarily, the "catalysts" discussed logistical issues, such as capacity for new users and coordinating transportation to users. In one of the fixed teams, the "catalysts" and HTs were not located at the same workplace (an integrated team model), and communication rarely occurred outside of the meetings, which were held every second week.

Through observations of the work environment in the fixed structured teams, it appeared that the HTs were barely present at the office.

Typical features of the user interventions, in which both a PT and an HT were present, were that the PT was in charge of the information provided, the assessments conducted and the instructions regarding training exercises, while the HT stayed in the background.

The field observations indicated a clear division of labor, where the "catalysts" had the responsibility for conducting assessments and developing a reablement plan, while the HTs conducted interventions based on the predefined plans. This observation was in accordance with data from the interviews. One HT in a fixed reablement team described the division of labor as follows:

"My task is to carry out the exercises together with the user. First, the catalysts [PT, OT or nurse] pay them a visit. They, I guess, provide a plan together with the user. At that first visit, they talk about reablement and evaluate whether the user is a suitable candidate. [...]They do 
the SPPB and COPM, those tests you know, and normally they bring us [HTs] along on the second visit. Then, we review the plan and the PT supervises me in conducting some exercises, perhaps. [...] And then, after about two weeks, they join us again.” (HT)

A PT claimed that the clear distinction of division of labor was intended to utilize the different professions' expertise and knowledge and avoid chaos. She said the following:

"Our work is complementary because we have different tasks. We have different qualifications, so it would be unnatural that we all should do everything. I believe that we should do what we do best. I think that would have been... In such a large team as ours, that would simply have led to chaos. So, I believe that a firm structure on things is essential." (PT) One PT also argued that by entrusting the HT with the responsibility for executing the training sessions, they could serve a larger population compared with a traditional rehabilitation approach. Another PT justified the practice in which the HTs mainly executed the interventions, as follows: "We do not want to interfere much during the reablement period, since it should be a learning setting for the HTs. So, if we were to pursue and control them all the time, we could rather have done the work ourselves. It's the empowering mindset that strikes in, you know. That they get the responsibility for this...” (PT)

The characteristics of a flexible team were a flat structure in which all the team members, including the HTs, had equal responsibility for tasks. Both therapists and HTs conducted assessments and performed training interventions. Observations of meetings in these teams revealed that the HTs engaged in discussions on the same level as the therapists and nurses. Both formal and informal meetings contained professional discussions and knowledge exchanges. Since all the team members had visited most of the users, they all contributed to the discussions based on their specific expertise and experiences.

Observations of user sessions in which both the PT and the HT were present showed that, similar to the fixed structured teams, the PTs were leading the interventions. However, during the sessions, the HTs in the flexibly structured teams were more involved than those in the fixed teams. They frequently commented on the quality of the user's movement during exercises and made suggestions about changes to the technique. Typically, the PTs visited the users on a regular basis, 
which provided insights into the users' home situation and everyday function. A PT said the following:

"I find it interesting to observe situations like morning care, for example. It provides me with lots of information. I evaluate how the user get out of bed, how they achieve a stance position, how they manage to take a shower. The whole "package" is extremely valuable for me as a PT. [...] I get a holistic impression of the user and the whole situation. I mean... I don't only see the small things, I see the whole setting, and that's inspiring. It's motivating. " (PT)

One PT used the metaphor of Jack-of-all-trades to describe how she had to adjust to different tasks and settings and how this contributed to interdisciplinary cooperation:

"You turn into a Jack-of-all-trades in a way because that's how it is. How we have to work. If I step my little toe into an ADL [activity of daily living] assessment, I don't pull it back up. Instead, I stay in it and discuss the situation with the occupational therapist later on or bring her with me to observe, maybe. I would think that she should evaluate the situation together with me, for example. But I bring along what I see and the assessments I do." (PT)

Employees on these teams emphasized the importance of cooperation and preferred to work in pairs on several occasions. HTs also highlighted the importance of sufficient access to PT supervision. Our analysis revealed that the division of labor affected the assessments and training interventions as described in the following sections.

\section{$\underline{\text { Assessment }}$}

One characteristic of the assessments in all the reablement teams explored in this study was that they used the COPM and SPPB assessment tools. Figure 1 presents an excerpt of the performance of the SPPB test from an observed baseline assessment. The characteristics of this observation were applicable to all the teams observed. 
Figure 1: The PT and HT mark a distance of 4 meters on the floor and tell the user to walk this distance. The PT keeps an eye on her stopwatch throughout the test. When the user crosses the 4-meter mark, the PT reports the time to the HT, who writes it down on a form. The user is instructed to perform the test once more, and the second time, the PT says: "You are already faster". The user says that she feels disabled in standing straight up; "it resists when I'm about to...", and she demonstrates by exaggerating a flexed posture. The PT answers that this feeling might be associated with her hip operation. "Yes, this is where I feel restricted when extending", the user complains while pointing to her hip. The HT writes down the results from the stopwatch, and the PT moves on to the next exercise.

Figure 1: Observation of conduction of the 4-meter gait test, an element of the SPPB.

The PT focused on the quantified results in terms of counting seconds and did not respond to the patient's complaints about functional restrictions. One PT claimed that this test always resulted in the same conclusion of impaired strength, balance or gait function.

Typically, in the reablement teams with a fixed structure, the PT rarely performed assessments or specific examinations other than the standardized tests mentioned above. A PT from a fixed reablement team expressed the following:

“I never do any specific tests, like muscle length or specific strength [...] I don't do that ... I don't ask them to take off their pants or anything like that... or lay on a bench...[...] I mean... it's more like a conversation... I don't find it natural to assess any movements. Therefore, you know... the details... I don't describe them in the journal or talk to the HTs about it. " (PT)

Since the PTs in the fixed structured teams seldom visited the users, they claimed that it was the responsibility of the HTs to make continuous observations during the training process and to report the essential conditions to the "catalysts". One PT stated that the "system" could not be dependent on the PTs conducting the visits.

In the flexibly structured teams, the PT characteristically performed extended examinations and assessments in addition to the standardized tests. The PTs reported that they conducted functional analyses regarding the movement and structure of muscles and joints. One PT in a flexible team described how she performed a specific functional analysis when she considered it necessary:

"It's really fun if ... well, it's not fun if there is something wrong with the user. Anyway, it's interesting if it suddenly turns out that there is a little "slack" due to the hip, which means 
that maybe I should do an examination on the couch. That is real fun. I may just check if anything has happened, because "Mrs. Hansen" has fallen, for example, during the weekend. If she complains about increasing pain due to the exercises we do... Check out if there is anything... Is there any pain caused by, for example, traction, retraction? Is the range of motion equal on both sides? Could it be hip osteoarthritis that is causing more pain?" (PT)

The PTs in flexible teams visited the users on a regular basis, which enabled consecutive assessments throughout the rehabilitation process. The example in Figure 2 shows how the PTs obtained more information about users' functions by analyzing their movement during a training session.

Figure 2: The user stands beside the kitchen worktop in a gait position and receives instructions to lift both her arms toward the ceiling. The PT observes that the user does not achieve the full range of extension in one hip. While standing close to the user, the PT lays her hand on the anterior part of the user's hip and the other hand behind the sacrum and says, "Eventually, you will get more straight up..." and gives a little push, facilitating hip extension. The user complains about a feeling of tightness in front of her hip. The PT moves her hand on the user's back higher up toward the thoracic region and facilitates extension of the column, asking "Can you feel the tightness even more now? You can feel that it pulls your posture down".

Figure 2: Observation of additional assessment.

Regular PT involvement with users was perceived by the respondent to be a core component of the flexible reablement teams, as one HT stated:

"Yes, she [the PT] is very dutiful in regularly being among the users. Additionally, to see how it goes and stuff, she wants to be updated. She is there, somehow, all the way. I think it is very good, that she is regularly present to observe and maybe consider doing some other exercises or advancing them. She [the user] has this problem with her foot... Yeah, so that's what I think she [the PT] will check out when she comes tomorrow." (HT)

The PTs also noted the importance of visiting the users together with the HT, as these joint meetings could result in useful discussions and exchange of knowledge.

The next section presents how different specifics of the assessments resulted in different intervention contents. 


\section{$\underline{\text { Intervention }}$}

Observations of the practice revealed that reablement plans contained elements of both exercise and daily activities. The exercises mainly targeted balance, leg strength and gait endurance, whereas daily activities could involve getting dressed, showering, and walking to the grocery store.

For the teams with a fixed division of labor, PTs characteristically initiated interventions concerning exercise regimens, while the HTs generally initiated activity training, which tended to be considered less important. In the interviews, a PT in a fixed structured team stated the following about activity training:

"I'm kind of not involved in that [...] It may happen that the HTs are like ... more focused on the exercises - strength and balance and so on. They forget the user's goals. Preparing food is a particularly common goal, but it is rarely tried out. So now I try to be a bit like, "you have to do...", because it is no point to do the closing session if they say "I didn't try it" or "I don't know." (PT)

During the observations of the fixed structured teams, standardized training programs written on a sheet, such as the "Helbostad exercises" or the "Otago Exercise Program"ii were applied. One PT confirmed that this was characteristic of a typical reablement approach in a fixed structured team:

"The training is seldom about technique, or whatever you call it. To get dressed, take a shower... That is stuff that the user has done all her life. So, in reablement it is like... we should train on preparing a meal, but it is actually nothing to really train on. She has prepared meals for years. She knows how to do it. She just needs ... I mean... we always fall back on the physical functions, really. Balance training and strength training. That is the core of everything. " (PT)

Figure 3 demonstrates how a user appears to question the relevance of the exercise she has been given. The HT cannot provide a clear answer to her concern, but tries to motivate her to complete her exercise program. 
Figure 3: The HT instructs the user to walk sideways while supporting her hands on the kitchen counter. The user asks why she has to walk sideways, to which the HT answers, "Because you are supposed to work on your walking". User: "But I walk so much otherwise". The HT assures the user that this exercise is familiar to her and says, "Soon we will walk outside (which is the user's main goal), so you will need some strength in your legs, right? We are going out for a walk soon". The user asks when they will be going out. $\mathrm{HT}$ : "One day. When the weather gets better". User: "One day, yes... What day?" $\mathrm{HT}$ : "We'll think about that". Then, she shifts the topic of conversation.

Figure 3: Observation of instructions of a non-specific exercise.

Another reason for using the general exercise programs was that they did not require much instruction or supervision, which simplified the transfer of exercises from the PT to both the HT and the user.

On the flexible teams, training for daily activities in addition to exercises was an important component of interventions. Video observations revealed details of clinical adjustments in the training sessions due to the user's individual physical ability, decline and experience of movement. Both PTs and HTs continuously corrected the execution of exercises in terms of quality and technique and were sensitive to changes in the user's functional level. Figure 4 presents an excerpt of an Intervention in which the PT and HT conducted a training session with the user. The PT analyzed the movement in detail and adjusted the exercises accordingly to target the problem, in this case motor ability. In doing so, the PT intervention addressed the user's goals and the functional limitations. During the observations, the PTs explained the purpose of an exercise and promoted bodily awareness of the user.

Figure 4: The PT instructs the user to climb the stairs. While watching the user from behind, the PT moves her eyes from the foot to the hip, then back to the foot again. Suddenly she turns her head slightly toward the HT and asks "Do you see that?" while she points toward the user's right foot, which constantly moves in a barely noticeable circular motion during the swing phase. This attention toward details of the user's movement makes the PT adjust the intervention program to involve exercises that specifically focus on the hip abductors and flexors.

Figure 4: Observation of the PTs distinct attention to small details of movement.

In flexibly structured teams that reported sufficient PT resources, HTs stated in the interview that this type of intervention was exciting and educational. In contrast, an HT from a team with poor 
PT resources found it challenging to implement complex training interventions. One HT stated a preference for standardized exercises in some cases:

"It's not my subject in a way. I just have to do my best and listen to what she [the PT] has to say [...] No, I don't find it very easy. To evaluate what is the right exercise, no, that's not my subject, really. That's my experience. At least if there are any limitations, pain for example, if they are in pain or they feel that it takes... that they are exhausted afterwards, or... No. No. In some cases, we have these typical 'Helbostad' exercises, where we do those four exercises. Thirty on each, you know. That is more tangible. But in the more diffuse cases, it is not that simple, I think." (HT)

Both PTs and HTs in flexibly structured teams preferred to visit the user together as a pair as often as possible to optimize the professional supervision and exchange of knowledge.

\section{$\underline{\text { DISCUSSION }}$}

As described, two main typologies of reablement teams emerged, namely a fixed and a flexible structured team. This subdivision of reablement differs from the earlier described organizational models of "specialist teams" and "integrated teams", and it demonstrates that reablement practices vary considerably within the same organizational model. Models of reablement must not be perceived as homogenous practices. Physiotherapy assessments and interventions were found to differ according to division of labor. In teams with a fixed structure, the assessments were limited to standardized measurement tools, and the devised rehabilitation plans mainly involved general exercise programs. In teams with a flexible structure, assessments of physical function were conducted in addition to standardized measurements. PTs were more involved in the process and interventions appeared to be more individually tailored and adapted to the user's goals and functional decline. We have used Hood's (1991) concept of organizational values to discuss how conflicting values in health care services may provide a varied practice across different reablement teams. 


\section{$\underline{\text { Conflicting values in fixed structured reablement teams }}$}

The fixed structured teams emphasized reaching a large proportion of the population in a resource-efficient way. Defining clear distinctions between tasks counteracted an excessive use of resources. According to Hood (1991), this structure is an example of practice based on what he refers to as Sigma-type organizational values, which emphasize frugality and characterize output-oriented management with limited slack for using more resources than absolutely necessary.

The main practice of these fixed organized teams was a streamlined service based on standardized assessment tools and general exercise programs and were hardly individually tailored. A qualitative interview study indicated that standardized training programs are insufficient in reablement (Hjelle, Tuntland, Forland, and Alvsvag, 2017) and several studies have suggested that reablement initiatives should be individually tailored (Cochrane, et al., 2016; Lewin, Concanen, and Youens, 2016; Legg, Gladman, Drummond, and Davidson, 2016; Newton, 2012). A flexible intervention with oppourtunities for employees to be creative has been reported as a success factor of reablement (Rabiee and Glendinning, 2011; Tessier, Beauliei, Mcginn, and Latulippe, 2016).

All users got similar initiatives, which is compatible with organizational values referred to as Theta-type values (Hood, 1991), which emphasize transparency and fairness of service. .This seemed to compromise the quality of the physiotherapy assessments and initiatives and services offered to the users. This finding also corresponds with the results of a study where efforts to make home care organizations more transparent and well run made staff less sensitive to the specific contexts of individuals' lives (Vabø, 2012).

Health care services are unstable and unpredictable and require a high degree of discretion. A lack of discretion may result in a variety of therapeutic challenges (Schmid and Hasenfeld, 1993). These reflections support our conclusions about the constraints in flexibility and individuality of the fixed structured reablement teams. 


\section{Conflicting values in flexible structured reablement teams}

The more thorough assessment and ongoing evaluation of practice in the reablement teams with a flexible structure enabled a user centered assessment and an intervention sensitive to users' abilities, restrictions and goals.

Several of the team members visited the user and influenced the reablement process with complementary knowledge. The involvement of different team members enabled interprofessional collaboration based on clinical discussions that combined and utilized the potential of professional diversity. Labor was broadly defined and shared problem solving was essential. This organizational structure is consistent with practices emphasizing Lambda-type values (Hood, 1991).

The Lambda-type values allows space for learning and adaptation and a high degree of slack and adaptivity regarding users' characteristics and unpredictable circumstances. However,. flexible structured reablement teams require thorough supervision, frequent visits by the PT, and visits with both PTs and HTs present at the same time. This may conflict with the values of efficiency and frugality and the flexible practice may be a more resource-demanding way of organizing reablement. Cost effectiveness across different reablement practices should be further evaluated.

The results of this study revealed that, compared to fixed structured reablement teams, PTs and HTs in flexibly structured teams provided user centered interventions. Literature has argued that reablement approaches should target individual goals and focus on activities that people are themselves motivated to do to impact on the user's sense of autonomy in everyday life (Gregory, Mackintosh, Kumar, and Grech, 2017; Newton, 2012). Additionally, this article argues that it is likely that services should be individually tailored due to physical ability and constraints. Potentially, this practice may be preferable from a long-term perspective in terms of the reduced needs for home care services and hospitalization and enhanced user satisfaction. Larger studies are needed to investigate this assumption.

\section{Cross-professional teamwork}

In reablement teams with a fixed division of labor, the content of practice tended to be more standardized and formally described to ensure that almost anyone could perform the intervention. This 
form of labor leaned toward what Freidson (1999) refers to as mechanical specialization and cannot be categorized as professional work, which requires discretion based on theoretical knowledge and skills and tailoring to each situation. From this perspective, it seems reasonable to ask whether a professional, such as a PT, is necessary in reablement teams in which the tasks are simplified and standardized in such a manner that anyone can perform them.

However, in the flexibly structured teams, the tasks were more varied, and the interventions were based on physiotherapy knowledge, which would qualify as what Freidson (1999) denotes as theoretically based discretionary specialization. This practice requires a high level of both professional knowledge and skills to work successfully.

In addition to a more thorough professional approach, a deeper level of collaboration was observed in the flexibly structured teams in this study. This occurred through in-depth discussions, shared practices and multiple meeting points. Literature has suggested that traditional multiprofessional work is not sufficient in home based rehabilitation services. Cooperation should consist of an even closer interprofessional interaction and collaboration to provide integrated and complementary services (Mitchell, Parker, Giles, and White, 2010; Moran, Nancarrow, Enderby, 2015; Ness, et al., 2012; Thylefors, Persson, and Hellstrom, 2005).

A continuum based on collaborative intensity among the team members defines three different team structures of cross-professional teamwork: multiprofessional, interprofessional and transprofessional teams. Multiprofessional teams consists of different disciplines working independently, but sharing information with each other. Interprofessional teams implies a higher level of communication, shared planning and mutual decision-making. Transprofessional teams are characterized by integrative work and partly dissolved boundaries between disciplines (Thylefors, Persson, and Hellstrom, 2005).

The structural factors characteristic of flexible teams, namely, collocation and a large number of informal meeting points, do not by themselves secure interprofessional cooperation. However, they enable social interaction among co-workers. The close collaboration, shared tasks and common goals generated by working together with the same user resulted in a perception of common responsibility 
for a task. The flat structure reduced the asymmetric relationship between co-workers, allowing for mutual participation in professional discussions, in accordance with transprofessional teamwork.

The same collaboration pattern did not appear in the fixed structured teams. In these teams, the employees assessed and treated users independently and then shared information later on, as is characteristic in multi-professional practice (Thylefors, Persson, and Hellstrom, 2005). Structural issues, such as different locations, rigidly defined divisions of labor and limited common insight inhibited the possibility of discretionary problem solving. Thylefors, Persson, and Hellstrom (2005) reported that the closer the collaboration, the higher the effeciency and the better the work climate. To a certain extent, the fixed practice may contribute to a disintegrated professional practice, which can cause a fragmented user care (Kodner 2002).

\section{Limitations}

Our results stem from a limited number of participants and teams, and other ways of structuring physiotherapy practice in reablement may exist. However, the two typologies illustrated in this study are relevant to similar reablement teams with regard to analytic generalizations, in accordance with Malterud (2001). Only one of the teams in this study was organized as an "integrated model" of reablement, organized in home care services, while the six other teams were organized as "specialist teams" independent from home care services. The integrated team had a stereotypical fixed structure, as described in this paper. However, we cannot draw conclusions from this single unit about definitive relationships between organizational models and content of practice and further research on organizational models is required. In this study, PTs and HTs were the main subjects, while other team members contributed through discussions and interactions in the work environment during field work. Nevertheless, collaboration between all team members should be further investigated. Reablement users were not interviewed, and their perspective of the service provided was not taken into account.

In this study, the included PTs recruited the users for participation. This design may have potentially caused bias. The important subjects of this study were the PT practice and the service provided to the users by the HTs. We considered the potential for bias to be of less importance concerning the aim of this exploratory study. 


\section{CONCLUSION}

We found that reablement involved a wide range of variation in the content of practice. How the teams distributed tasks internally influenced the intervention. Two typologies of reablement teams appeared: fixed structured teams and flexibly structured teams. This study showed that clinical reasoning and individualized approaches were limited when teams had a distinct and predefined division of labor. Furthermore, a flexibly structured team, with fewer formal distinctions between work tasks, promoted more thorough assessments and tailored interventions based on interprofessional discussions between team members. However, the flexible structure required sufficient physiotherapy resources and frequent supervision of HTs.

\section{$\underline{\text { Implications for practice and further research }}$}

This study highlights how different structures of labor provide the opportunity for varied practices among PTs and for different contents of health care services. Both PTs and municipality management staff should be aware of how an imbalance in management values may result in unintended consequences for the implementation of physiotherapy practice in reablement. Previous effect studies have addressed reablement as a homogeneous service. However, this study reveals diverse reablement practices. Our findings call for attention to cooperation between team members, especially in PTs' supervision of HTs in the transfer of knowledge. Further studies on work practices in reablement are needed. It is important for both health care leaders and municipal administrators to be aware of how administrative values influence health care practices and the quality of services. In this sense, this study contributes to the ongoing international debate about human service organization and management.

\section{Acknowledgments}


We would like to thank all the participants, co-workers and administrative employees on the included reablement teams. We acknowledge the Norwegian Fund for Post-Graduate Training in Physiotherapy for funding the study.

\section{Declaration of interest}

The authors declare no conflicts of interest. 


\section{REFERENCES}

Andrews T 2012 What is social constructionism. Grounded Theory Review 11: 39-46.

Aspinal F, Glasby J, Rostgaard T, Tuntland H, Westendorp RG 2016 New horizons: Reablement supporting older people towards independence. Age and Ageing 45: 572-576.

Carswell A, McColl MA, Baptiste S, Law M, Polatajko H, Pollock N 2004 The Canadian Occupational Performance Measure: A research and clinical literature review. Canadian Journal of Occupational Therapy 71: 210-222.

Cochrane A, Furlong M, McGilloway S, Molloy DW, Stevenson M, Donnelly M 2016 Time-limited home-care reablement services for maintaining and improving the functional independence of older adults. Cochrane Database of Systematic Reviews 10: CD010825.

Førland O, Skumsnes R 2016 Hverdagsrehabilitering-En oppsummering av kunnskap [reablement- A litterature review]. file:///C:/Users/mae029/Downloads/hverdagsrehabilitering\%20(2).pdf.

Freidson E 1999 Theory of professionalism: Method and substance. International review of sociology 9: 117-129.

Fürst \& Høverstad ANS 2014 Fra passiv mottaker til aktiv deltaker [from passive recipient to active participant]. [Online] Available from: http://www.ks.no/globalassets/blokker-til-hvertfagomrade/ny-mappe/ks---hverdagsrehabilitering---sluttrapport-endelig.pdf.

Gomez JF, Curcio CL, Alvarado B, Zunzunegui MV, Guralnik J 2013 Validity and reliability of the Short Physical Performance Battery (SPPB): A pilot study on mobility in the Colombian Andes. Colombia Medica 44: 165-171.

Gregory A, Mackintosh S, Kumar S, Grech C 2017 Experiences of health care for older people who need support to live at home: A systematic review of the qualitative literature. Geriatric Nursing 38: 315-324.

Heath C, Hindmarsh J, Luff P 2011 Video in qualitative research. London, SAGE Publication Ltd.

Heath C, Luff P, Svensson MS 2007 Video and qualitative research: Analysing medical practice and interaction. Medical Education 41: 109-116. 
Helbostad JL, Sletvold O, Moe-Nilsen R 2004 Effects of home exercises and group training on functional abilities in home-dwelling older persons with mobility and balance problems. A randomized study. Aging clinical and experimental research 16: 113-121.

Hjelle KM, Tuntland H, Forland O, Alvsvag H 2017 Driving forces for home-based reablement: A qualitative study of older adults' experiences. Health \& Social Care in the Community 25: $1581-1589$.

Hood C 1991 A public management for all seasons? Public Administration 69: 3-19.

Johnson J, Thompson AJ 1996 Rehabilitation in a neuroscience centre: The role of expert assessment and selection. British Journal of Therapy and Rehabilitation 3: 303-308.

Kodner D 2002 Integrated care: meaning, logic, applications, and implications - a discussion paper. International journal of integrated care 2: 1-6.

Kyrdalen IL, Moen K, Røysland AS, Helbostad JL 2014 The Otago Exercise Program Performed as Group Training Versus Home Training in Fall-prone Older People: A Randomized Controlled Trial. Physiotherapy Research International 19: 108-116.

Langeland E, Førland O, Aas E, Birkeland A, Folkestad B, Kjeken I, Jacobsen FF, Tuntland H 2016 Modeller for hverdagsrehabilitering-en følgeevaluering i norske kommuner. [Models for everyday rehabilitation - a follow-up evaluation in Norwegian municipalities]. [Online] Available from: https://brage.bibsys.no/xmlui/bitstream/handle/11250/2389813/1/Rapport6_16_web.pdf 18.04.2017.

Legg L, Gladman J, Drummond A, Davidson A 2016 A systematic review of the evidence on home care reablement services. Clinical Rehabilitation 30: 741-749.

Lewin G, Concanen K, Youens D 2016 The home independence program with non-health professionals as care managers: an evaluation. Clinical interventions in aging 11: 807-817.

Malterud K 2001 Qualitative reasearch: Standards, challenges, and guidelines. Lancet 358: 483-488. Malterud K 2012 Systematic text condensation: A strategy for qualitative analysis. Scandinavian Journal of Social Medicine 40: 795-805. 
Malterud K 2016 Theory and interpretation in qualitative studies from general practice: Why and how? Scandinavian Journal of Social Medicine 44: 120-129.

Mitchell R, Parker V, Giles M, White N 2010 Review: Toward realizing the potential of diversity in composition of interprofessional health care teams: An examination of the cognitive and psychosocial dynamics of interprofessional collaboration. Medical Care Research and Review 67: 3-26.

Moe A, Brataas HV 2016 Interdisciplinary collaboration experiences in creating an everyday rehabilitation model: a pilot study. Journal of multidisciplinary healthcare 9: 173-182.

Moran A, Nancarrow S, Enderby P 2015 Mechanisms to enhance the effectiveness of allied health and social care assistants in community-based rehabilitation services: a qualitative study. Health \& Social Care in the Community 23: 389-398.

Ness NE, Laberg T, Haneborg M, Granbo R, Færevaag L, Butli H 2012 Hverdagsmestring og hverdagsrehabilitering [Everyday Coping and everyday rehabilitation]. [Online] Available from: file:///C:/Users/mae029/Downloads/Rapport\%20Hverdagsrehabilitering\%20031012.pdf 18.04.2017.

Newton C 2012 Personalising reablement: inserting the missing link. Working with Older People: Community Care Policy \& Practice 16: 117-121.

Norwegian Centre for Research Data 2017 NSD. http://www.nsd.uib.no/nsd/english/index.html Acessed: 11.12.2017

Norwegian Ministry of Health and Care Services 2015 Meld. St. 26 (2014-2015) Fremtidens primærhelsetjeneste - nærhet og helhet [The primary health and care services of tomorrow localised and integrated]. https://www.regjeringen.no/contentassets/d30685b2829b41bf99edf3e3a7e95d97/engb/pdfs/stm201420150026000engpdfs.pdf.

Pettersson C, Iwarsson S 2017 Evidence-based interventions solving occupational therapists are needed in re-ablement for older community-living people: A systematic review. British journal of occupational therapy 80: 273-285.

QSR International What is NVivo. http://www.qsrinternational.com/ Accessed: 03.04.2017. 
Rabbiee P, Glendinning C 2011 Organisation and delivery of home care re-ablement: what makes a difference? Health \& social care in the community 19: 495-503.

Ryburn B, Wells Y, Foreman P 2009 Enabling independence: restorative approaches to home care provision for frail older adults. Health \& social care in the community 17: 225-234

Schmid H, Hasenfeld Y 1993 Organizational dilemmas in the provision of home-care services. Social Service Review 67: 40-54.

Sims-Gould J, Tong CE, Wallis-Mayer L, Ashe MC 2017 Reablement, Reactivation, Rehabilitation and Restorative Interventions With Older Adults in Receipt of Home Care: A Systematic Review. J Am Med Dir Assoc 18: 653-663.

Tessier A, Beaulieu MD, Mcginn CA, Latulippe R 2016 Effectiveness of reablement: a systematic review. Healthcare Policy 11: 49-59.

Tinetti ME, Baker D, Gallo WT, Nanda A, Charpentier P, O'Leary J 2002 Evaluation of restorative care vs usual care for older adults receiving an acute episode of home care. JAMA 287: 20982105.

Thylefors I, Persson O, Hellstrom D 2005 Team types, perceived efficiency and team climate in Swedish cross-professional teamwork. Journal of Interprofessional Care 19: 102-114.

Tuntland H, Aaslund MK, Langeland E, Espehaug B, Kjeken I 2016 Psychometric properties of the Canadian Occupational Performance Measure in home-dwelling older adults. Journal of Multidisciplinary Healthcare 9: 411-423.

Vabø M 2012 Norwegian home care in transition - heading for accountability, off-loading responsibilities. Health and Social Care in the Community 20: 283-291.

World Confederation for Physical Therapy 2016 What is physical therapy. http://www.wcpt.org/whatis-physical-therapy Accessed: 17.01.17.

World Medical Association 2017 WMA declaration of Helsinki - Ethical principles for medical research involving Human Subjects. https://www.wma.net/policies-post/wma-declaration-ofhelsinki-ethical-principles-for-medical-research-involving-human-subjects/ Accessed:

11.12.2017 
i An exercise program consisting of four exercises for leg strength and balance: sit-to-stand, knee lift, toe stand and knee bend in a weight-bearing position (Helbostad, Sletvold, and Moe-Nilssen, 2004).

ii A home-based balance and strength program documented to prevent falls (Kyrdalen, Moen, Røysland, and Helbostad, 2014).

Tabl e 1: Inf or mati on about the PTs, HTs and users.

\begin{tabular}{|c|c|c|c|}
\hline Parti d pants & Gender & Experi ence & User goals \\
\hline PTs & $\begin{array}{l}\text { Female: } \mathrm{n}=6 \\
\text { Male: } \mathrm{n}=1\end{array}$ & $\begin{array}{l}\text { Novice }(<5 \text { years as a PT): } n=2 \\
\text { Experienced }(>5 \text { years as a PT): } \\
n=5\end{array}$ & \\
\hline HTs & $\begin{array}{l}\text { Female: } n=7 \\
\text { Male: } n=0\end{array}$ & $\begin{array}{l}\text { Experience from home care } \\
\text { practice: } n=3 \\
\text { Experience from institutional } \\
\text { care practice: } n=3 \\
\text { Experience from both: } n=1\end{array}$ & \\
\hline Users & $\begin{array}{l}\text { Female: } n=7 \\
\text { Male: } n=0\end{array}$ & & $\begin{array}{l}\text { Showering, cooking, going to the } \\
\text { mall, attending the day care } \\
\text { center, walking outside, } \\
\text { household chores, walking } \\
\text { up/down stairs, walking } \\
\text { independent of human } \\
\text { assistance, walking inside with a } \\
\text { walking stick, feeling safe at } \\
\text { home, traveling alone by public } \\
\text { transport. }\end{array}$ \\
\hline
\end{tabular}

Table 2: Analysis process inspired by Malterud (2012).

$\left.\begin{array}{|l|l|l|l|l|}\hline \begin{array}{l}\text { Step 1) overall } \\ \text { impressions }\end{array} & \begin{array}{l}\text { Audiotaped } \\ \text { interviews }\end{array} & \multicolumn{1}{|l|}{\begin{array}{l}\text { Videotaped } \\ \text { observations }\end{array}} & \begin{array}{l}\text { Field notes } \\ \text { from work } \\ \text { environment } \\ \text { observations }\end{array}\end{array}\right\}$


Table 3: Characteristics of reablement teams.

\begin{tabular}{|l|l|l|l|}
\hline \multicolumn{2}{|c|}{} & \multicolumn{2}{c|}{ Division of labor } \\
\cline { 3 - 4 } \multicolumn{2}{|l|}{} & $\begin{array}{l}\text { Fixed structure } \\
\text { (1 team with integrated } \\
\text { model, 3 teams with } \\
\text { specialist model) }\end{array}$ & $\begin{array}{l}\text { Flexible structure } \\
\text { (3 teams with specialist } \\
\text { model) }\end{array}$ \\
\hline \multirow{2}{*}{ Organization } & Team leader & Yes & No \\
\cline { 2 - 4 } & Schematic distribution of tasks & Yes & No \\
\hline \multirow{2}{*}{ Assessment } & Use of COPM and SPPB & Yes & Yes \\
\cline { 2 - 4 } & Complementary assessments & No & Yes \\
\hline Intervention & General approach based on standardized \\
& programs & Yes & Some \\
\cline { 2 - 4 } & Individually tailored training & No & Yes \\
\cline { 2 - 4 } & Training on daily activities & Some & Yes \\
\hline
\end{tabular}

